Jurnal Sulolipu : Media Komunikasi Sivitas Akademika dan Masyarakat

Vol. 21 No.12021

e-issn : 2622-6960, p-issn : 0854-624X

\title{
Identifikasi Gas Karbon Monoksida Di Persimpangan Jalan Sultan Alauddin Kota Makassar
}

The Identification Of Monoxide Carbon Gas In The Junction Of Sultan Alauddin Roads, Makassar City

Inayah ${ }^{1}$, dan Andi Ruhban ${ }^{2}$, Hamsir Ahmad ${ }^{3}$

1,2,3 Jurusan Kesehatan Lingkungan Poltekkes Kemenkes Makassar

*)inayahmahmud.500@gmail.com

\section{ABSTRACT}

Carbon Monoxide or $\mathrm{CO}$ is a colorless, odorless, non-irritating gas resulting from incomplete combustion processes. The purpose of this study is to find out how much carbon monoxide levels at the Sultan Alauddin intersection of Makassar City. This type of research is descriptive research by performing measurements directly at two point location. The tools used are Odalog and Hygrothermometer. The results showed that carbon monoxide content at point $I$ is at the T-junction Monumen Emmy Saelan-Sultan Alauddin in the morning of $9508.57 \mu \mathrm{g} / \mathrm{Nm}^{3}$, during the day of $7748.57 \mu \mathrm{g} / \mathrm{Nm}^{3}$ and the afternoon of $13302.85 \mu \mathrm{g} / \mathrm{Nm}^{3}$ and on the second point is at the T-junction Sultan Alauddin-A.P Pettarani in the morning of $8571,42 \mu \mathrm{g} / \mathrm{Nm}^{3}$, daytime at $5645,71 \mu \mathrm{g} / \mathrm{Nm}^{3}$ and afternoon at $6902,85 \mu \mathrm{g} / \mathrm{Nm}^{3}$. The results of the measurements show below the ambient air quality standards specified under South Sulawesi Governor Regulation no. 69 of 2010 on Quality Standards and Criteria for Environmental Damage.

Keywords : Carbon Monoxide

\section{ABSTRAK}

Karbon Monoksida atau CO merupakan gas yang tidak berwarna, tidak berbau, dan tidak mengiritasi yang dihasilkan dari proses pembakaran tidak sempurna. Tujuan penelitian ini untuk mengetahui seberapa besar kadar Karbon Monoksida di persimpangan jalan Sultan Alauddin Kota Makassar. Jenis penelitian ini merupakan penelitian deskriptif dengan melakukan pengukuran secara langsung pada dua titik lokasi. Alat yang digunakan adalah Odalog dan Hygrothermometer. Hasil penelitian menunjukkan bahwa kandungan karbon monoksida pada titik I yaitu di pertigaan jalan Monumen Emmy Saelan-Sultan Alauddin pada pagi hari sebesar $9508,57 \mu \mathrm{g} / \mathrm{Nm}^{3}$, siang hari sebesar 7748,57 $\mu \mathrm{g} / \mathrm{Nm}^{3}$ dan sore hari sebesar $13302,85 \mu \mathrm{g} / \mathrm{Nm}^{3}$ dan pada titik II yaitu di Pertigaan Jl. Sultan Alauddin-A.P Pettarani pada pagi hari sebesar $8571,42 \mu \mathrm{g} / \mathrm{Nm}^{3}$, siang hari sebesar $5645,71 \mu \mathrm{g} / \mathrm{Nm}^{3}$ dan sore hari sebesar 6902,85 $\mu \mathrm{g} / \mathrm{Nm}^{3}$. Hasil pengukuran menunjukkan dibawah standar baku mutu udara ambien yang ditetapkanberdasarkan Peraturan Gubernur Sulawesi Selatan No. 69 Tahun 2010 Tentang Baku Mutu dan Kriteria Kerusakan Lingkungan Hidup.

Kata Kunci : Karbon Monoksida

\section{PENDAHULUAN}

Udara merupakan faktor yang penting dalam kehidupan, namun dengan meningkatnya pembangunan fisik kota dan pusat-pusat industri, kualitas udara telah mengalami perubahan. Udara yang dulunya segar, kini kering dan kotor. Pada sore hari dari ketinggian tampak kota besar seperti Jakarta memperlihatkan warna yang kumuh, cakrawala yang diliputi asap dan debu. Hal ini bila tidak segera ditanggulangi, perubahan tersebut dapat membahayakan kesehatan manusia, kehidupan hewan serta tumbuhan (Soedomo, 2001).

Sejalan dengan perkembangan pada daerah perkotaan, keseimbangan komposisi udara terganggu bahkan komposisinya berubah yaitu dengan masuknya zat-zat pencemar seperti polutan kendaraan bermotor menghasilkan $85 \%$ dari seluruh pencemaran udara yang terjadi. Kendaraan bermotor ini merupakan pencemar bergerak yang menghasilkan pencemar $\mathrm{CO}$, hidrokarbon yang tidak terbakar sempurna, $\mathrm{NO}_{x}, \mathrm{SO}_{x}$ dan partikel debu. Pencemaran udara yang lazim dijumpai pada berbagai tempat khususnya di kota-kota besar (Kamal, 2015).

Asap kendaraan merupakan sumber utama bagi karbon monoksida di berbagai perkotaan. Data mengungkapkan bahwa $60 \%$ pencemaran udara di Jakarta disebabkan karena benda bergerak atau transportasi umum yang berbahan bakar solar terutama berasal dari Metromini (Sugiarti, 2009).

Berdasarkan data pencemar di kota besar, perlu dilakukan identifikasi polutan khususnya gas karbon monoksida CO di Kota Makassar terutama di persimpangan jalan Sultan Alauddin (belokan jalan Monumen Emmy Saelan dan belokan jalan A.P.Pettarani) sebagai salah satu zona terpadat lalu lintas pada kurun Maret 2020.

\section{METODE PENELITIAN}

\section{Lokasi Penelitian}

Lokasi penelitian dilakukan di persimpangan Jl. Sultan Alauddin Kota Makassar di titik-titik yang padat kendaraan yaitu dilakukan di dua titik yaitu titik I di pertigaan jalan Monumen Emmy Saelan - 
Jurnal Sulolipu : Media Komunikasi Sivitas Akademika dan Masyarakat

Vol. 21 No. 12021

e-issn : 2622-6960, p-issn : 0854-624X

Sultan Alauddin dan titik II di pertigaan jl. Sultan Alauddin - A.P Pettarani.

\section{Variabel Penelitian}

Varibel bebas dalam penelitian ini yaitu sumber pencemar (kendaraan bermotor) pada udara di pagi, siang dan sore hari sedangkan variabel terikatnya yaitu kadar $\mathrm{CO}$ yang berasal dari kendaraan di Persimpangan Jl. Sultan Alauddin.

\section{Definisi Operasional}

a. Objek dalam penelitian ini yaitu udara ambient dengan parameter Karbon Monoksida, di mana CO yang dimaksud adalah banyaknya kadar CO yang bersumber di titik lokasi pengambilan sampel yakni di Persimpangan Jl. Sultan Alauddin Kota Makassar.

b. Kandungan Karbon Monoksida pada udara di titik I yaitu pertigaan Jalan. Monumen Emmy Saelan- jalan Sultan Alauddin dan titk II yaitu pertigaan JI. Sultan Alauddin-A.P Pettarani pada pengukuran yang dilakukan pada pagi, siang dan sore hari selama satu jam pengukuran terhadap kendaraan yang beroperasi atau yang melalui lokasi tempat penelitian.

\section{Kriteria Objektif}

a. Dikatakan memenuhi syarat jika hasil pemeriksaan menunjukkan di bawah standar $30.000 \mu \mathrm{g} / \mathrm{Nm}^{3}$ berdasarkan Peraturan Gubernur Sulawesi Selatan No. 69 Tahun 2010 Tentang Baku Mutu dan Kriteria Kerusakan Lingkungan Hidup.

b. Dikatakan tidak memenuhi syarat jika hasil pemeriksaan melebihi standar

atau di atas $30.000 \mu \mathrm{g} / \mathrm{Nm}^{3}$ berdasarkan Peraturan Gubernur Sulawesi Selatan No. 69 Tahun 2010 Tentang Baku Mutu dan Kriteria Kerusakan Lingkungan Hidup.

\section{Sampel}

Teknik pengambilan sampel yang digunakan yaitu Purposive Sampling yaitu dengan pertimbangan peneliti mengambil 2 titik karena melihat jumlah kepadatan kendaraan pada jam-jam padatnya kendaraan. Alat yang digunakan adalah Odalog dan Hygrothermometer

\section{TEKNIK PENGUMPULAN DATA}

\section{Data primer}

Data primer diperoleh dengan melakukan observasi dan pengukuran kadar $\mathrm{CO}$. Observasi lapangan dengan pengukuran langsung dan melihat langsung kondisi persimpangan Jl. Sultan Alauddin Kota Makassar.

\section{Data sekunder}

Data sekunder yang berfungsi sebagai data pendukung yaitu data yang diperoleh

dari hasil studi penelitian, website serta literatur-literatur yang ada hubungannya dengan objek penelitian.

\section{Analisa Data}

Data yang diperoleh berdasarkan hasil pengukuran lapangan diolah secara manual, kemudian disajikan dalam bentuk tabel dan dianalisa/ dilakukan interpretasi data secara deskriptif dengan menggunakan grafis. 
Jurnal Sulolipu : Media Komunikasi Sivitas Akademika dan Masyarakat

Vol. 21 No. 12021

e-issn : 2622-6960, p-issn : 0854-624X

\section{HASIL DAN PEMBAHASAN}

1. Hasil Penelitian

a. Kandungan Karbon Monoksida

Tabel 1

Hasil Pengukuran Kandungan Karbon Monoksida (CO)

\begin{tabular}{|c|c|c|c|c|}
\hline Lokasi & $\begin{array}{l}\text { Waktu } \\
\text { (WITA) }\end{array}$ & $\begin{array}{c}\text { Kandungan } \\
\text { co }\end{array}$ & Rata-rata & Baku Mutu \\
\hline Titik I & $07.00-$ & 9508,57 & \multirow{4}{*}{$\begin{array}{c}10186,66 \\
\mu \mathrm{g} / \mathrm{Nm}^{3} \\
(8,91 \mathrm{ppm})\end{array}$} & \multirow{4}{*}{$\begin{array}{l}30.000 \mu \mathrm{g} / \mathrm{Nm}^{3} \\
\text { (Memenuhi } \\
\text { Syarat) }\end{array}$} \\
\hline $\begin{array}{l}\text { Pertigaan Jalan Monumen Emmy } \\
\text { Saelan-Jalan Sultan Alauddin }\end{array}$ & $\begin{array}{l}08.00 \\
\text { (pagi) }\end{array}$ & $\begin{array}{c}\mu \mathrm{g} / \mathrm{Nm}^{3} \\
(8,32 \mathrm{ppm})\end{array}$ & & \\
\hline & $\begin{array}{l}12.00- \\
13.00 \\
\text { (siang) }\end{array}$ & $\begin{array}{c}7748,57 \\
\mu \mathrm{g} / \mathrm{Nm}^{3} \\
(6,78 \mathrm{ppm})\end{array}$ & & \\
\hline & $\begin{array}{l}15.00- \\
16.00 \\
\text { (sore) }\end{array}$ & $\begin{array}{c}13302,85 \\
\mu \mathrm{g} / \mathrm{Nm}^{3} \\
(11,64 \mathrm{ppm})\end{array}$ & & \\
\hline \multirow{7}{*}{$\begin{array}{c}\text { Titik II } \\
\text { Pertigaan Jalan Sultan Alauddin-Jalan } \\
\text { A.P Pettarani }\end{array}$} & $08.15-$ & 8571,42 & \multirow{7}{*}{$\begin{array}{c}7039,99 \\
\mu \mathrm{g} / \mathrm{Nm}^{3} \\
(6,16 \mathrm{ppm})\end{array}$} & \multirow{7}{*}{$\begin{array}{l}30.000 \mu \mathrm{g} / \mathrm{Nm}^{3} \\
\text { (Memenuhi } \\
\text { Syarat) }\end{array}$} \\
\hline & $\begin{array}{l}09.15 \\
\text { (pagi) }\end{array}$ & $\begin{array}{c}\mu \mathrm{g} / \mathrm{Nm}^{3} \\
(7,5 \mathrm{ppm})\end{array}$ & & \\
\hline & $13.15-$ & 5645,71 & & \\
\hline & $\begin{array}{c}14.14 \\
\text { (siang) }\end{array}$ & $\begin{array}{c}\mu \mathrm{g} / \mathrm{Nm}^{3} \\
(4,94 \mathrm{ppm})\end{array}$ & & \\
\hline & $16.15-$ & 6902,85 & & \\
\hline & 17.15 & $\mu \mathrm{g} / \mathrm{Nm}^{3}$ & & \\
\hline & (sore) & $(6,04$ ppm) & & \\
\hline
\end{tabular}

Sumber : Data Primer

b. Pengukuran Suhu

Tabel 2

Hasil Pengukuran Suhu

\begin{tabular}{cccc}
\hline Lokasi & Waktu & Suhu & Rata-rata \\
\hline Titik I & Pagi & $30,6^{\circ} \mathrm{C}$ & \\
\cline { 2 - 3 } Pertigaan Jalan Monumen Emmy & \multirow{2}{*}{$32,1^{\circ} \mathrm{C}$} \\
\cline { 2 - 3 } Saelan - Jalan Sultan Alauddin & Siang & $31,8^{\circ} \mathrm{C}$ & \\
\cline { 2 - 3 } Titik II & Sore & $34,1^{\circ} \mathrm{C}$ & \multirow{2}{*}{$32,7^{\circ} \mathrm{C}$} \\
\cline { 2 - 3 } $\begin{array}{c}\text { Pertigaan Jalan Sultan Alauddin- } \\
\text { Jalan A.P Pettarani }\end{array}$ & Pagi & $32,1^{\circ} \mathrm{C}$ & $32^{\circ} \mathrm{C}$ \\
\cline { 2 - 3 } & Siang & $34,2^{\circ} \mathrm{C}$ & \\
\cline { 2 - 3 } & Sore & &
\end{tabular}

Sumber : Data Primer

c. Hasil Pengukuran Kelembaban

Tabel 3

Hasil Pengukuran Kelembaban

\begin{tabular}{cccc}
\hline Lokasi & Waktu & Kelembaban & Rata-rata \\
\hline Titik I & Pagi & $73 \%$ & \\
\cline { 2 - 3 } Pertigaan Jalan Monumen Emmy & Siang & $64 \%$ & \multirow{2}{*}{$66 \%$} \\
\cline { 2 - 3 } Saelan - Jalan Sultan Alauddin & Sore & $61 \%$ & \\
\cline { 2 - 3 } Titik II & Pagi & $61 \%$ & \\
\cline { 2 - 3 } $\begin{array}{c}\text { Pertigaan Jalan Sultan Alauddin- } \\
\text { Jalan A.P Pettarani }\end{array}$ & Siang & $65 \%$ \\
\cline { 2 - 3 } & Sore & $50 \%$ &
\end{tabular}

Sumber : Data Primer 
Jurnal Sulolipu : Media Komunikasi Sivitas Akademika dan Masyarakat

Vol. 21 No. 12021

e-issn : 2622-6960, p-issn : 0854-624X

\section{Pembahasan}

Adapun analisa hasil berdasarkan hasil penelitian yang dilakukan di Persimpangan Jalan Sultan Alauddin Kota Makassar selama satu hari penelitian dengan dua titik lokasi dengan pengambilan sampel sebanyak tiga kali disetiap titik pengukuran yang berbeda periode waktunya yaitu pagi, siang dan sore hari.

Hasil pengukuran konsentrasi Karbon Monoksida dari dua titik dengan periode waktu pengambilan yaitu pagi, siang dan sore hari didapatkan hasil rata-rata pada titik I sebesar 8,91 ppm dan titik || sebesar 6,16 ppm yang masih di bawah standar berdasarkan Peraturan Gubernur Sulawesi Selatan No. 69 Tahun 2010 untuk Karbon Monoksida yaitu $30.000 \mu \mathrm{g} / \mathrm{Nm}^{3}$ atau $26 \mathrm{ppm}$.

Umumnya $\mathrm{CO}$ tidak menimbulkan masalah terhadap kesehatan pda konsentrasi alami. Efek yang membahayakan manusia telah diamati pada paparan $\mathrm{CO}$ pada konsentrasi 12 sampai $17 \mu \mathrm{g} / \mathrm{Nm}^{3}$ (1015 ppm) selama 8 jam. Pengaruh kesehatan terdiri atas tekanan fisiologikal, terutama pada penderita penyakit jantung, keracunan darah (Soedomo, 2001).

Walaupun hasil yang didapatkan masih di bawah standar berdasarkan Peraturan Gubernur Sulawesi Selatan No. 69 Tahun 2010 untuk Karbon Monoksida yaitu 30.000 $\mu \mathrm{g} / \mathrm{Nm}^{3}$ atau $26 \mathrm{ppm}$ akan tetapi dampak karbon monoksida terhadap manusia perlu diperhatikan karena karbon monoksida merupakan gas yang tidak berwarna tidak berbau, tidak berasa dan praktis tidak menyebabkan perangsangan pada saluran napas. Akibatnya, proses peracunan tidak disadari oleh korbannya (Sumardjo, 2008).

Faktor penting yang menentukan pengaruh $\mathrm{CO}$ terhadap tubuh manusia adalah konsentrasi $\mathrm{COHb}$ yang terdapat di dalam darah, di mana semakin tinggi persentase hemoglobin yang terikat dalam bentuk $\mathrm{COHb}$, semakin para pengaruhnya terhadap kesehatan manusia. Karbon monoksida bersaing dengan oksigen yang bercampur dengan hemoglobin. Produk yang terbentuk melalui kombinasi karbon monoksida dan hemoglobin disebut karboksihemoglobin, $\mathrm{COHb}$. Hemoglobin mempunyai sekitar 210 kali lebih afinitas terhadap karbon monoksida dibandingkan terhadap oksigen. Oleh sebab itu, lebih sedikit oksigen yang diambil oleh hemoglobin pada saat apapun ketika karbon monoksida ada (Fardiaz, 2008)
Dari hasil pengukuran tersebut, konsentrasi Karbon Monoksida di perempatan Jalan Monumen Emmy SaelanJalan Sultan Alauddin lebih tinggi dibandingkan konsentrasi kadar Karbon Monoksida di Pertigaan Jl. Sultan AlauddinA.P Pettarani. Ini menunjukkan bahwa tingkat pencemaran udara pada titik I lebih tinggi dibandingkan titik II.

Melihat perbedaan konsentrasi karbon monoksida pada titik I didapatkan hasil tertinggi yaitu pengukuran pada sore hari sebesar 11,64 ppm. Adapun hal-hal yang dapat mempengaruhi dengan hasil pengukuran pada pagi dan siang hari yaitu jumlah kendaraan, suhu dan kelembaban serta kecepatan angin. Pengukuran yang dilakukan pada pagi dan siang hari sangat dipengaruhi oleh cuaca di mana pada saat pengukuran cuaca sangat mendung dan saat pengukuran itu dilakukan pada bulan ramadhan sehingga aktivitas atau jumlah kendaraan pada pagi dan siang hari tidak begitu padat. Berbeda pada saat pengukuran yang dilakukan pada sore hari di mana kepadatan kendaraan mulai meningkat dibandingkan pada saat pengukuran pagi dan siang hari.

Sedangkan konsentrasi karbon monoksida pada titik II didapatkan hasil tertinggi yaitu pada pagi hari sebesar 7,5 ppm. Adapun hal yang dapat mempengaruhi tingginya kadar karbon monoksida pada pagi hari di titik II karena pengukuran dilakukan pada pukul 08.15 Wita di mana sebagian besar masyarakat kebanyakan memulai aktivitas pada jam demikian.

Berdasarkan data dari BLHD (Badan Lingkungan Hidup Daerah), pemantauan kualitas udara ambien 2014 untuk parameter CO di Pertigaan Sultan AlauddinAP.Pettarani didapatkan 1951,82 $\mu \mathrm{g} / \mathrm{Nm}^{3}$, tahun 2015 didapatkan $\mathrm{CO}$ pada pagi hari $919,68 \mu \mathrm{g} / \mathrm{Nm}^{3}$, siang hari 1562,08 $\mu \mathrm{g} / \mathrm{Nm}^{3}$, sore hari $2318,69 \mu \mathrm{g} / \mathrm{Nm}^{3}$ dan pada tahun 2016 didapatkan 3438,4 $\mu \mathrm{g} / \mathrm{Nm}^{3}$. Berdasarkan penelitian yang dilakukan oleh Ruhban dkk (2018), hasil pengukuran CO pada siang hari di Pertigaan jalan Sultan Alauddin-jalan A.P.Pettarani didapatkan $92,10 \mu \mathrm{g} / \mathrm{Nm}^{3}$. Ini menunjukkan bahwa adanya peningkatan kadar $\mathrm{CO}$ di udara dipengaruhi oleh tingkat kepadatan kendaraan. Selain itu juga, jenis bahan bakar yang umum digunakan adalah premium yang menghasilkan $\mathrm{CO}_{x}$ dan $\mathrm{NO}_{x}$ dalam jumlah yang relatif besar jika dibandingkan dengan 
pertamax dan pertalite yang menghasilkan $\mathrm{CO}_{x}$ dan $\mathrm{NO}_{x}$ dalam jumlah yang relatif sangat sedikit dibandingkan dengan premium.

Konsentrasi $\mathrm{CO}$ di udara ambient dipengaruhi oleh besarnya laju aliran gas $\mathrm{CO}$ dan $\mathrm{NO}_{2}$ tersebut, kondisi kestabilan cuaca, kecepatan angin, suhu, serta kelembaban udara (Pamekas, 2013).

Pengukuran dapat dipengaruhi berbagai faktor pada lokasi penelitian. Seperti halnya suhu dan kelembaban. Suhu yang didapatkan pada Titik I yaitu $32^{\circ} \mathrm{C}$ dan Titik II yaitu $32,7^{\circ}$ C. Suhu udara dapat mempengaruhi konsentrasi pencemar udara. Suhu udara yang tinggi menyebabkan udara makin renggang sehingga konsentrasi pencemar menjadi makin rendah. Sebaliknya pada suhu yang dingin keadaan udara makin padat sehingga konsentrasi pencemar di udara tampaknya makin tinggi (Mukono,2008).

Kualitas udara ambien juga dipengaruhi oleh kecepatan angin. Kecepatan angin merupakan salah satu faktor yang menentukan kandungan karbon monoksida karena CO pada udara di lokasi penelitian akan terbawa oleh angin sesuai kecepatan angin. Selain itu, pepohonan dan bangunan yang ada di lokasi penelitian tersebut akan sangat mempengaruhi konsentrasi karbon monoksida di udara. Semakin banyak bangunan pada lokasi pengukuran maka akan mempengaruhi banyaknya kandungan CO karena tidak adanya ruang gerak udara yang akan membawa karbon monoksida dari lokasi tersebut menjauh. Ternyata tanah yang masih terbuka di mana belum ada bangunan di atasnya, dapat membantu penyerapan gas $\mathrm{CO}$. Hal ini disebabkan mikroorganisme yang ada di dalam tanah mampu menyerap gas $\mathrm{CO}$ yang terdapat di udara (Wardhana, 2004).

Selain itu, kepadatan kendaraan bermotor merupakan salah satu faktor utama yang menentukan jumlah kandungan karbon monoksida (CO) di udara ambient dan menjadi penyumbang utama dari berbagai faktor lainnya karena mengingat jumlah kendaraan yang semakin meningkat jumlahnya sehingga emisi yang dihasilkan kendaraan bermotor semakin banyak.

Karena kendaraan bermotor merupakan sumber polutan $\mathrm{CO}$ yang utama maka daerah-daerah yang berpenduduk padat dengan lalu lintas ramai memperlihatkan tingkat polusi $\mathrm{CO}$ yang tinggi. Konsentrasi $\mathrm{CO}$ di udara per waktu dalam satu hari dipengaruhi oleh kesibukan atau aktivitas kendaraan bermotor yang ada. Semakin ramai kendaraan bermotor yang ada, semakin tinggi tingkat polusi $\mathrm{CO}$ di udara.

Solusi yang bisa dilakukan untuk mengurangi kadar $\mathrm{CO}$ di udara yaitu dengan mengganti bahan bakar yang umum digunakan masyarakat, melakukan penghijauan/penanaman pohon di lokasilokasi yang padat kendaraan (Fardiaz, 2008)

Adapun keterbatasan dalam penelitian ini yaitu peneliti tidak melakukan pengukuran kecepatan angin. Selain itu tidak dilakukan replikasi pengukuran sehingga tidak didapatkan data yang akurat.

\section{KESIMPULAN DAN SARAN}

\section{Kesimpulan}

Berdasarkan hasil penelitian pengukuran Karbon Monoksida (CO) di Persimpangan Jalan Sultan Alauddin Kota Makassar, maka penulis dapat menyimpulkan sebagai berikut:

a. Kandungan karbon monoksida (CO) pada titik I yaitu di perempatan jalan Monumen Emmy Saelan - jalan Sultan Alauddin didapatkan rata-rata kandungan CO sebesar 10186,66 $\mu \mathrm{g} / \mathrm{Nm}^{3}$.

b. Kandungan karbon monoksida (CO) pada titik II yaitu di Pertigaan Jalan Sultan Alauddin- jalan A.P. Pettarani didapatkan rata-rata kandungan $\mathrm{CO}$ sebesar 7039,99 $\mu \mathrm{g} / \mathrm{Nm}^{3}$.

Hasil pengukuran menunjukkan di bawah standar $\quad 30.000 \mu \mathrm{g} / \mathrm{Nm}^{3}$ berdasarkan Peraturan Gubernur Sulawesi Selatan No. 69 Tahun 2010 Tentang Baku Mutu dan Kriteria Kerusakan Lingkungan Hidup.

\section{Saran}

Dari hasil penelitian yang dilakukan, peneliti menyarankan :

a. Sebagai masyarakat pengguna jalan atau yang berada di sekitar jalan Sultan Alauddin Kota Makassar sebaiknya menggunakan APD (Alat Pelindung Diri) untuk meminimalkan dampak yang ditimbulkan.

b. Pemerintah perlu melakukan penghijauan (penanaman pohon) khusunya di perkotaan yang padat lalu lintas untuk membantu proses penyerapan gas karbon monoksida.

c. Sebaiknya masyarakat mengganti jenis bahan bakar kendaraan yang digunakan seperti pertalite atau pertamax yang lebih ramah lingkungan. 
Jurnal Sulolipu : Media Komunikasi Sivitas Akademika dan Masyarakat

Vol. 21 No. 12021

e-issn : 2622-6960, p-issn : 0854-624X

\section{DAFTAR PUSTAKA}

Andi Ruhban dan Indah Rahmadana. 2018 Analisis Konsentrasi Karbon Monoksida (CO) Dan Sulfur Dioksida $\left(\mathrm{SO}_{2}\right)$ Udara Pada Sumber Bergerak Di Jalan A.P Pettarani Dan Rapoccini Raya Kota Makassar. (Online) http://journal.poltekkesmks.ac.id/ojs2/index.php/Sulolipu/article/view/723 volume 18 nomor 1 halaman 74-78

Damin Sumardjo. 2008. Pengantar Kimia: Buku Panduan Kuliah Mahasiswa Kedokteran dan Program Strata I Fakultas Bioeksakta. (J. S. Amalia Hanif, Juli Manurung, Ed.). Jakarta: EGC.

G. S. Sodhi. 2015. Konsep Dasar Kimia Lingkungan. (T. R. Ningsih, Ed.) (3rd ed.). Jakarta: EGC.

H. J. Mukono. 2008. Pencemaran Udara dan Pengaruhnya terhadap Gangguan Saluran Pernapasan (3rd ed.). Surabaya: Airlangga university Press.

Melati Ferianita Fachrul. 2012. Metode Sampling Bioekologi. Jakarta:Bumi Aksara

Muhammad Akib. 2014. Hukum Lingkungan (Perspektif Global dan Nasional) (2nd ed.). Jakarta: Rajawali Pers.

Muhammad Ikhwan. 2011. Studi Kepadatan Kendaraan Bermotor Dan Kandungan Karbon Monoksida (CO) Pada Udara Di Dua Traffic Light Jalan Hertasning Kota Makassar. Makassar : Program Diploma III Jurusan Kesehatan Lingkungan Politeknik Kesehatan Makassar. (Karya Tulis IImiah tidak diterbitkan)

Moestikahadi Soedomo. 2001. Pencemaran Udara. Bandung: ITB.

Nahlah Mustafa Kamal 2015. Studi Tingkat Kualitas Udara Pada Kawasan Mall Program Studi Teknik Lingkungan. Makassar : Program Studi Teknik Lingkungan Jurusan teknik Sipil Fakultas teknik Universitas Hasanuddin Makassar, (Online), (http://repository.unhas.ac.id, diakses 13 Januari 2017)

Nunung Nurhayati. 2013. Pencemaran Lingkungan (1st ed.). Bandung: CV Yrama Widya.

Republik Indonesia. 1999. Peraturan Pemerintah No. 41 Tahun 1999, tentang Pengendalian Pencemaran Udara, (41), 1-34.

R. Pamekas. 2013. Perlindungan dan Pengelolaan Lingkungan Kawasan Pemukiman (1st ed.). Bandung: PT. Dunia Pustaka Jaya.

Sugiarti. 2009. Gas Pencemar Udara Dan Pengaruhnya Bagi Kesehatan Manusia Air Pollutan Gasses and The Influence of Human Healt, 50-58, (Online), (http://ojs.unm.ac.id, diakses 13 Januari 2017)Srikandi Fardiaz. 2008. Polusi Air \& Udara. Yogyakarta: Kanisius.

Wisnu Arya Wardhana. 2004. Dampak Pencemaran Lingkungan (3rd ed.). Yogyakarta: Andi. 